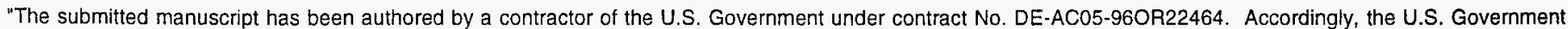

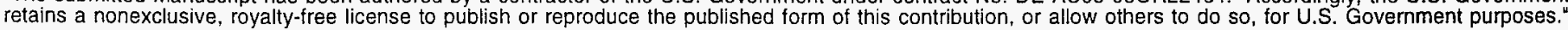

\title{
MULTIVARIATE STATISTICAL ANALYSIS OF LOW-VOLTAGE EDS SPECTRUM IMAGES
}

Ian M. Anderson

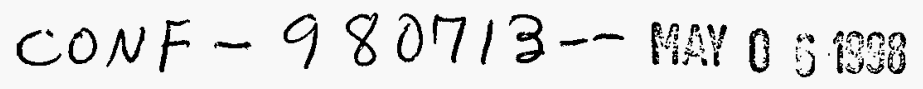

Metals \& Ceramics Division, Oak Ridge National Laboratory, PO Box 2008, Oak Ridge, TN 3731

Whereas energy-dispersive X-ray spectrometry (EDS) has been used for compositional analysis in the scanning electron microscope (SEM) for 30 years, the benefits of using low ( $\leq 5 \mathrm{kV}$ ) operating voltages for such analyses have been explored only during the last few years. ${ }^{1-4}$ This paper couples low-voltage EDS with two other emerging areas of characterization: spectrum imaging and multivariate statistical analysis (MSA). The specimen analyzed for this study was a finished Intel Pentium processor, with the polyimide protective coating stripped off to expose the final active layers. Data acquisition was performed with a Philips XL30-FEG SEM operated at $2 \mathrm{kV}$ and equipped with an Oxford super-ATW detector and XP3 pulse processor. The specimen was normal to the electron beam and the take-off angle for acquisition was $35^{\circ}$. The microscope was operated with a $150 \mu \mathrm{m}$ diameter final aperture at spot size 6 , which yielded an X-ray count rate of $\sim 1000 \mathrm{~s}^{-1}$. EDS spectra were acquired as DTSA files and EDS spectrum images were acquired as Adobe Photoshop files, each with the corresponding 4pi plug-in module. (The spectrum images could also be stored as NIH Image files, but the raw data are automatically rescaled as maximum-contrast (0-255) 8-bit TIFF images, which poses an inconvenience for quantitative analysis.) The 4pi plug-in module used for the spectrum imaging is designed for EDS Xray mapping and allows simultaneous acquisition of maps from 48 elements plus an SEM image. The spectrum image was acquired by re-defining the energy intervals of 48 elements to form a series of contiguous $40 \mathrm{eV}$ windows from $0.12 \mathrm{kV}$ to $2.00 \mathrm{kV}$. A spectrum image of $512 \times 384$ pixels was acquired from a $90 \times 67.5 \mu \mathrm{m}$ area of the specimen $(\sim 175 \mathrm{~nm} /$ pixel $)$ with a dwell time of 0.2 live seconds per pixel, for a total acquisition time of $\sim 14 \mathrm{~h}$. The binary data files were imported into Mathematica for analysis with software developed by the author at Oak Ridge National Laboratory. ${ }^{5,6} \mathrm{~A}$ $256 \times 192$ pixel section (one quarter) of the original image was analyzed. MSA required $\sim 150$ Mbytes of memory and $\sim 2.5$ h of CPU time on a $300 \mathrm{MHz}$ Power Macintosh 9600.

The results of this study are shown in Fig. 1. The SE image in (a) shows two distinct background grey levels, a bright central strip and two darker flanking areas, corresponding to an $\mathrm{SiO}_{2}$ layer and two $\mathrm{Al}(\mathrm{Cu})$ lines, which were deposited as the last active layers of the device. Superimposed on these two grey levels is topological contrast from underlying layers of the chip. Image I0 in (b) gives the average X-ray intensity levels in the spectrum image; it is the image that would be acquired with a non-dispersive $X$-ray detector. The two phases each have a distinct grey level, the $\mathrm{SiO}_{2}$ being brighter because of the high intensity of the O-K X-rays. The black regions in (b) are areas of the specimen that are shadowed from the EDS detector, which is situated to upper right. The width of the dark diagonal strip suggests that the $\mathrm{Al}(\mathrm{Cu})$ lines are $\sim 2 \mu \mathrm{m}$ thick. Image $\mathrm{I} 1 \mathrm{in}(\mathrm{c})$ has similar features to $\mathrm{I} 0$, with some contrast reversal. The corresponding component spectrum $\mathrm{E} 1$ in (e) shows that the contrast in $\mathrm{I} 1$ arises from the differences in characteristic $\mathrm{X}$-ray signals from the $\mathrm{SiO}_{2}$ and the $\mathrm{Al}(\mathrm{Cu})$ regions of the specimen. Additional $\mathrm{C}$ and $\mathrm{F}$ signals also correlate positively with the $\mathrm{Al}(\mathrm{Cu})$ signal, although these surface contaminants are also present on the $\mathrm{SiO}_{2}$, and result from a $\mathrm{CF}_{4}$ etch that was used to strip the polyimide from the chip. This chemical variation is the information that we desire from X-ray microanalysis. In contrast, image $\mathrm{I} 2$ in (d) shows mainly the topological contrast of the SE image, with the chemical variations - the background grey levels of Fig. 1 - filtered out! Spectral component E2 in (f) shows a positive correlation of the C and $\mathrm{F}$ signals and a negative correlation with the signal from the $\mathrm{SiO}_{2}$. Note the different intensity scales in (e) and (f). The similarity between images (a) and (d) shows that the detection of $\mathrm{C}$ and $\mathrm{F}$ correlates strongly with secondary electron emission. The origin of this correlation is most likely specimen charging, with additional buildup of mobile $\mathrm{CF}_{\mathrm{x}}$ surface contaminants at regions of higher SE emission.

1. C.E. Nockolds, Microbeam Analysis 3(1994)185; Proc. Microscopy \& Microanalysis 1996, 476.

2. E. Boyes, Proc. 13th ICEM: Electron Microscopy 1994 1(1994)51.

3. M.T. Johnson et al., Proc. Microscopy \& Microanalysis 1996, 478.

4. D.E. Newbury, Proc. Microscopy \& Microanalysis 1997, 881. 
5. I.M. Anderson and J. Bentley, Mater. Res. Soc. Symp. Proc. 458(1997)81.

6. I.M. Anderson and J. Bentley, Proc. Microscopy \& Microanalysis 1997, 931.

7. Research at the Oak Ridge National Laboratory (ORNL) SHaRE User Facility was sponsored by the Division of Materials Sciences, U.S. Department of Energy, under contract DE-AC05-960R22464 with Lockheed Martin Energy Research Corporation. The author thanks David Susnitzky of Intel for furnishing the specimen and Jim Bentley of ORNL for helpful discussions about the data acquisition.

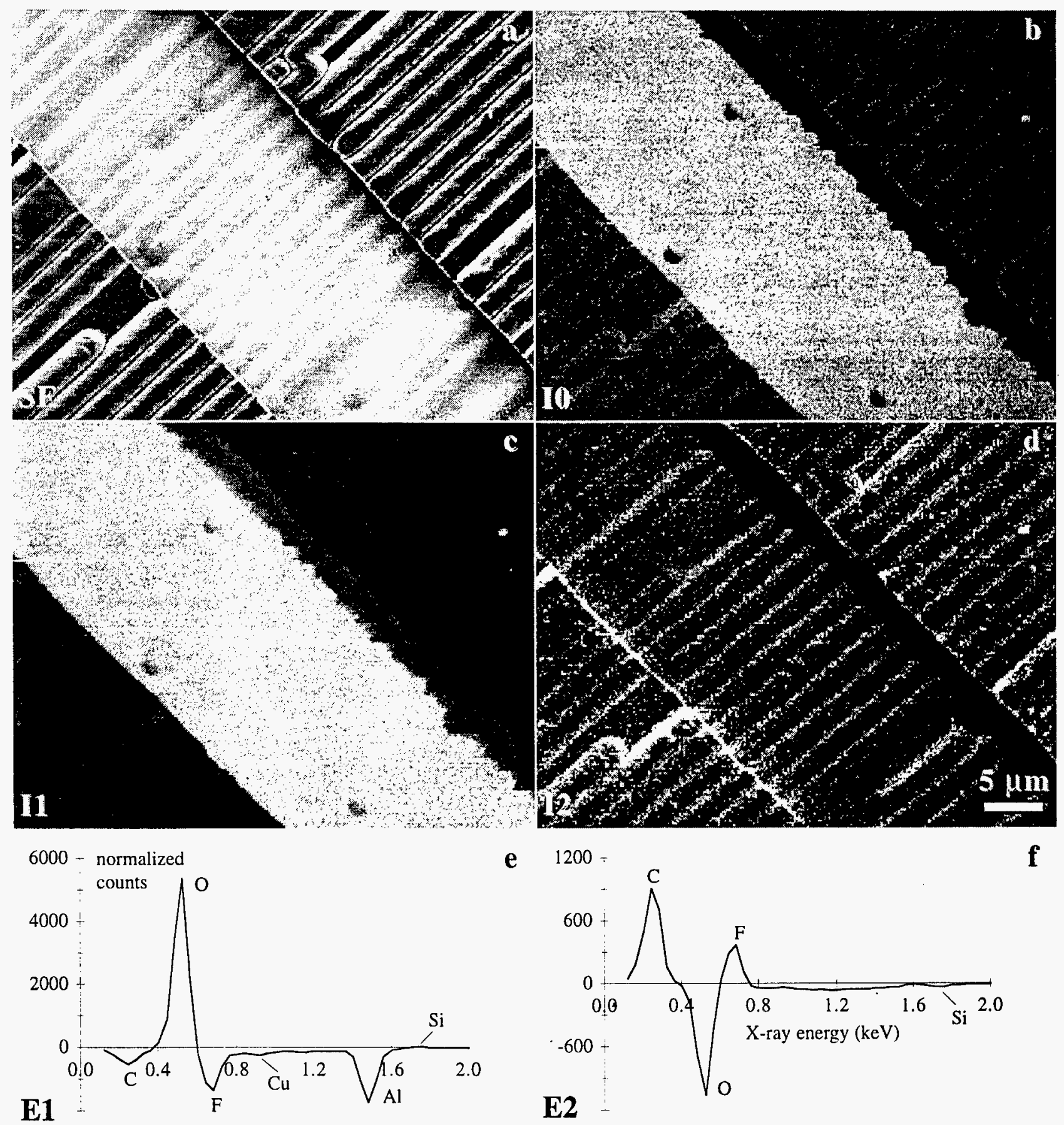

Fig. 1 (a) SE image of the analyzed area. MSA components (b) I0, (c) I1 \& (d) I2 of the EDS spectrum image. Component spectra (e) E1 \& (f) E2 corresponding to images I1 \& I2. 


\section{DISCLAIMER}

This report was prepared as an account of work sponsored by an agency of the United States Government. Neither the United States Government nor any agency thereof, nor any of their employees, makes any warranty, express or implied, or assumes any legal liability or responsibility for the accuracy, completeness, or usefulness of any information, apparatus, product, or process disclosed, or represents that its use would not infringe privately owned rights. Reference herein to any specific commercial product, process, or service by trade name, trademark, manufacturer, or otherwise does not necessarily constitute or imply its endorsement, recommendation, or favoring by the United States Government or any agency thereof. The views and opinions of authors expressed herein do not necessarily state or refiect those of the United States Government or any agency thereof. 


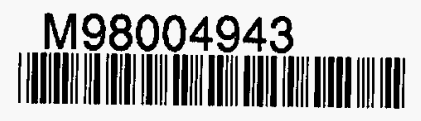

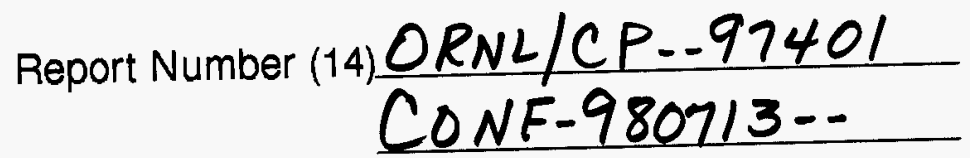

Publ. Date (11) 199803
Sponsor Code (18) DOE/ER, XF
UC Category (19) UC-40D, DOE/ER

19980619068 